\title{
Wild Edible Fruit Species Cultural Domain, Informant Species Competence and Preference in Three Districts of Amhara Region, Ethiopia
}

\author{
Fentahun Mengistu and Herbert Hager
}

\section{Research}

\begin{abstract}
The study was carried out in Adiarkay, Debark and Dejen districts in a context where wild fruit bearing species suffer notable disregard from research and development strategies, and consequently the basic information remains verbally with the local people without being adequately documented. Free-listing, individual interviews, focus group discussions, direct observation and pair-wise ranking were used to glean and evaluate data. Altogether, 46 species make up the wild fruits domain of the study area. Each site and district appeared to have its own cultural domain, and salient and favorite species. There is a high correspondence between highly preferred and salient species. Aggregating free-list data to solicit a cultural domain of the highest stratum (study area) was found to highly underestimate the domains of lower strata (districts and sites). There exists a wealth of knowledge about wild fruit species, especially on the part of the youth, shedding light on the perpetuation of indigenous knowledge. Future studies on wild fruits in the area needs to capitalize on species identified to have high consent and should make use of informants identified as having high species competency.
\end{abstract}

\section{Introduction}

The value of wild edible plants to sustained people in a variety of parts of the world has been well documented (Grivetti \& Ogle 2000, Redzic 2007). In Ethiopia, it is estimated that 200 species of wild/semi-wild species are widely used (Edwards 1992, Getachew et al. 2005, Mesfin 1997). Edible fruit bearing species form one of the most important local survival strategies. This is particularly important because their consumption has been reported to be more common and widespread in food insecure areas (Getahun 1974, Guinand \& Dechassa 2000).
In spite of their importance, wild edible plants, especially fruit bearing species, suffer notable disregard from research and development plans in Ethiopia, particularly in the Amhara region. Thus they remain inadequately documented. Basic information pertaining to wild fruit species is available from the local people who are the custodians of these resources and knowledge about them (Demel \& Abeje 2004). At present, due to the catastrophic destruction of their natural habitats, wild edible plant resources are degrading fast along with the associated indigenous knowledge. Yet, documentation and preservation of this knowledge in the country remains scanty (Demel \& Abeje 2004, Getachew et al. 2005). As such, assessment and better understanding of the wild fruit resources and associated knowledge is crucial. As a step in this direction, the study made use of local peoples' knowledge to define the cultural domain of wild fruits.

Cultural domains are important starting points for studying peoples' perceptions of the natural world and are important aspects of local/indigenous knowledge by which cultural organizations are understood (Puri \& Vogl 2005). Hence, defining cultural domains from an emic perspec-

\section{Correspondence}

Fentahun Mengistu, Amhara Regional Agricultural Research Institute, P.O.Box 527, Bahir Dar, ETHIOPIA.

fentahunmen@yahoo.com

Herbert Hager, Department of Forest and Soil sciences, Institute of Forest Ecology, Boku University of Natural Resources and Applied Life Sciences, Peter-Jordan Street 82, A- 1190 Vienna, AUSTRIA.

Herbert.hager@boku.ac.at

Ethnobotany Research \& Applications 6:487-502 (2008)

Published: December 31, 2008

www.ethnobotanyjournal.org/vol6/i1547-3465-06-487.pdf 
tive enables us to elicit lists of cultural domain elements that are considered by the local people as being members of a particular domain (Borgatti 1994, 1996). Elements of a cultural domain can be understood through free-listing method (Martin 1995), which has been successfully used by several researchers for eliciting cultural domains or as a precursor for further studies (Albuquerque \& OIiveira 2007, Castaneda 2004, Castaneda \& Stepp 2007, Khanh et al. 1999, Lykke 1998, Mourão et al. 2006, Quinlan 2005, Wong et al. 2002). In this paper, we sought to define the content and structure of the wild edible fruit tree/shrub species cultural domain and explore the associated knowledge, perception and preferences of people at varying sampling scales of analysis. In addition, we examine factors responsible for intra- and inter-site informant variations with respect to species competence and preference.

\section{Methodology}

\section{Study sites}

The study was undertaken in Adiarkay, Debark and Dejen districts of Amhara region, Northwestern Ethiopia during the period August 2006 to January 2007. Part of the North Gondar Administrative Zone, Adiarkay $\left(13.25^{\circ} \mathrm{N}, 38.02^{\circ} \mathrm{E}\right)$ and Debark $\left(13.08^{\circ} \mathrm{N}, 37.54^{\circ} \mathrm{E}\right)$ districts are located adja- cent to each other at the northeastern and western fringes of the slopes of Semen Mountains bordered by Tigray region in the north, east and northwest. The Tekeze River defines the eastern border of Adiarkay district. The Dejen district $\left(10.13 \mathrm{~N}^{\circ}, 38.81 \mathrm{E}^{\circ}\right)$ is located in East Gojjam Administrative Zone, at the southwestern end of the Amhara region through which the region shares a border with the Oromiya region in the south. The Blue Nile River delimits the study site, Kurar. The study area is situated at an elevation between 1200 and $3400 \mathrm{~m}$ above sea level. Climatically, Adiarkay and Dejen have a warm temperate climate that tends to be hot to warm moist towards the specific study sites while it is cool at Debark, especially in the highlands. Adiarkay, Debark and Dejen districts respectively receive an average yearly precipitation between $900-1800 \mathrm{~mm}, 400-1200 \mathrm{~mm}$ and $900-1200 \mathrm{~mm}$. Steep slopes, rugged ridges and ravines characterize the terrains of most part of the study sites. Acrisols form the major soil types in Debark, Cambisols and Leptosols in Adiarkay while Dejen (Kurar site) is dominated by large deposit of Rendzians mixed with eutric cambisols. Geologically, both Adiarkay and Debark are a formation of tertiary plateau volcanoes while Dejen (Kurar site) is a Mesozoic sedimentary rock (BoPED 1999).

The inhabitants are dependent upon their natural environment and the majority make a living out of subsistence mixed farming (crop and livestock production). Compound-

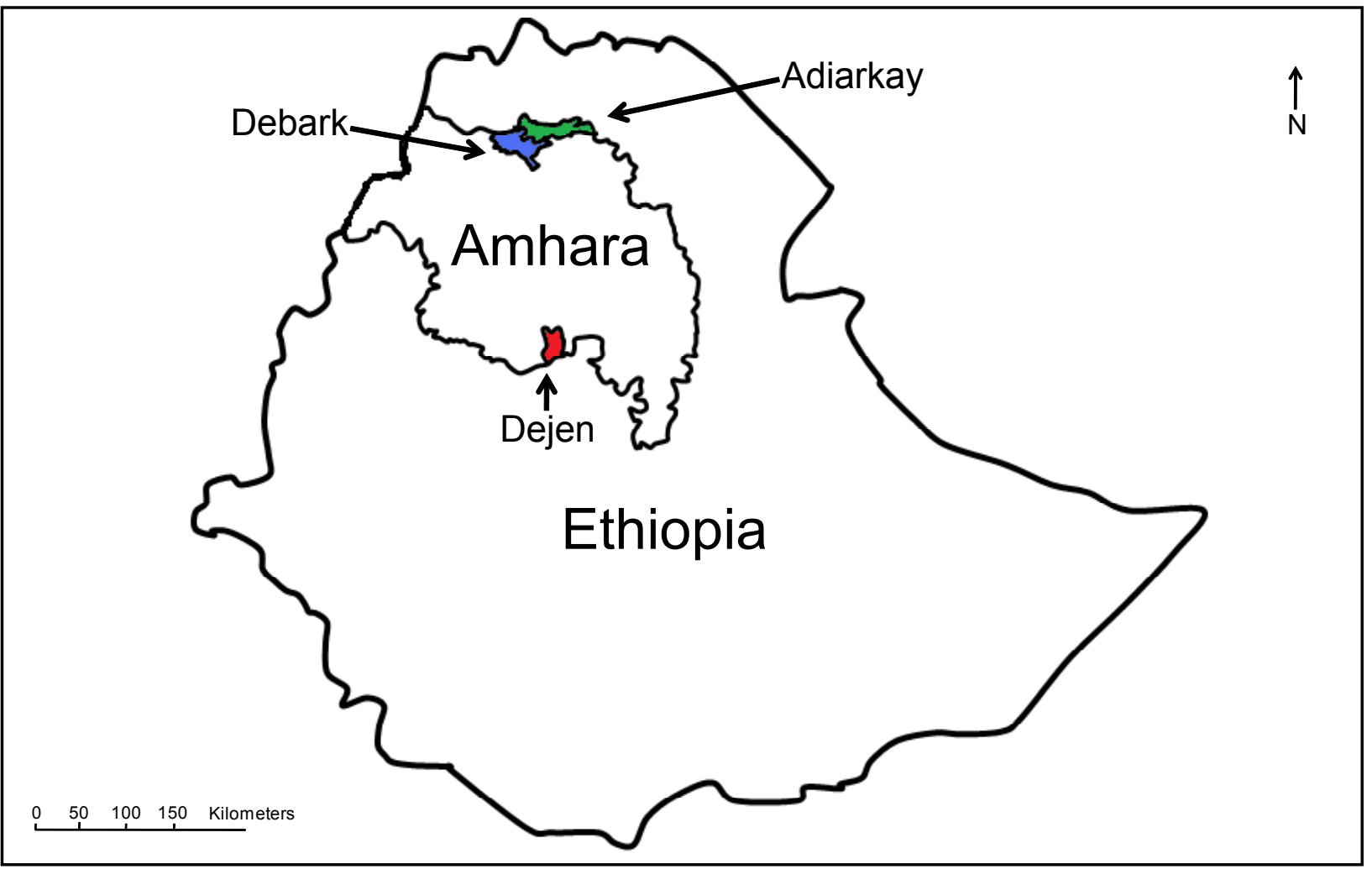

Figure 1. Map of the study area in Amhara region of Ethiopia. 
ed by a fragile environmental setting, the study areas figure among the chronic food insecure areas periodically facing food shortages. People are, therefore, poor and a large proportion of the populace in Adiarkay and Debark districts manage to survive on food aid. Christianity is the dominant religion, with Orthodox sects forming the majority especially among rural inhabitants. Islamic people are few in the rural settings. The majority of the people are Amhara nationals whose mother tongue is Amharic. This is the regional as well as the national official language. A few people are Tigre or members of other ethnic groups. A few are bilingual speaking Amharic and Tigrinya.

\section{Data collection and Analysis}

Five Peasant Associations (hereafter called sites) were chosen in the three districts: Adiaregay and Bermariam in Adiarkay, Debir and Dibbahir in Debark and Kurar in Dejen. A free-list technique was employed to elicit information about the cultural domain of wild edible fruit plant species from informants. This is an effective method that can even be used with children or illiterate people (Sinha 2003). Semi-structured interviews were administered with 104 randomly chosen informants stratified by age and sex (12-27 informants from each site). Informants were asked independently the same question to freely name orally all the wild edible fruit species they know as it comes into their memory. Their answers were noted verbatim in the order given (Puri \& Vogl 2005). Data were also collected on informants' attributes: age, gender, education status and number of children. This was done to be able to relate their social status with their species competence. Reflections on species preferences of people were assessed both through individual interviews of informants and in groups, of which the latter exercised pair-wise ranking (Maundu 1995). In addition, in accompanied excursions with key informants the researcher paid field visits to observe the plants cited to gather additional information.

Several of the wild fruit species were identified in the field with the help of informants and agricultural development experts, and their botanical names established by referring to available literatures and researchers' own experiences. For species which could not be confirmed on the spot voucher specimens were transported to the National Herbarium of Addis Ababa University where they were identified and specimens deposited at.

The free-list data was analyzed at three levels; study area, district and site. It was summarized for species frequency, average rank, Smith's salience index (Smith 1993) as well as free-list length of informants. To determine the cultural domain of wild fruits, we adopted the rule suggested by Borgatti (1996) that only species cited by at least two informants were considered for inclusion. This was done on the grounds that agreement between two individuals was the absolute minimum requirement for viewing an item as more than idiosyncratic. Smith's salience index was used to judge species saliency by weighing the average of the inverse rank of a species across multiple free-lists where each list was weighted by the number of species in the list. ANTHROPAC (Borgatti 1992) was used to generate Smith's salience indexes.

The co-occurrence of species and distance in rank between species in the free-lists were used as a simple proxy for similarity of fruits in the domain (Castaneda \& Stepp 2007, Sinha 2003). For this the free-list data was dichotomized and only positive matches considered. The proximity data was then input to construct fruit cluster diagrams for which average linkage distance-based hierarchical agglomerative clustering method was employed. In addition, a non-metric multidimensional scaling (NMDS) map was used to visualize the fruit species in a two-dimensional space. This algorithm by considering the rank order of the input proximitiy yields a negative relationship where larger input values correspond to smaller map distances (DeJordy et al. 2007). The degree of correspondence between the distances among points implied by the non-metric multidimensional scaling map and the input matrix was judged through a stress function, where a stress level 0.15 and less was taken as acceptable (Borgatti 1996).

Consensus analysis was done to capture variations in competence and culture of informants, identify species that would be listed by typical informants and generate a consensus key or model of right answers at study area, district and site levels. A reliability measure (pseudo-reliability) closer to the value one and factor loadings in Eigenvalue table, where the ratio of the first factor to a second is 3:1 or greater, were taken as a measure of high consensus and single culture origin of informants. The influence of socio-demographic variables on fruit species knowledge of informants was explored through a general linear modeling (GLM) regression technique where negative binomial-GLM with a log link was used. Frequencies and a chi-square test were respectively used to summarize the informants' free-list length and its correlation with age. Species preference was estimated from pair-wise rankings of group discussants and summaries of individual preference responses. All data analyses with respect to cultural domain and consensus analysis were performed in a series of steps using the ANTHROPAC 4.0 software (Borgatti 1992). Statistical Package for the Social Sciences (SPSS) 2006 for Windows, Version 15, was additionally employed to summarize the free-list data.

\section{Results and Discussion}

\section{The wild fruits domain}

In the free-listing exercise, informants across the study areas volunteered altogether the names of more than 50 species. On average, each informant listed 9.6 species 
that ranged from as low as three to a maximum of 23 . Three-quarters of the informants were able to mention 12 or fewer species. This is shown by the slightly right skewed histogram in Figure 3, where the frequency of mention progressively declines as the length of free-lists increases. After excluding species of single informant frequency, 46 species were retained to constitute the wild fruits domain of the entire study area (Figure 2). The rare species are left out because only species that are in active use are expected to be cited with a high frequency. Hence, the low-frequency species are considered to be either in passive use or used only in some idiolects (Sutrop 2001).

In addition, analysis of the free-list data by disaggregating into district and site levels showed a similar pattern where a few species occur at higher frequencies. Each locality appeared to have its own respective domain with some level of species sharing with others (Table 1). At district level, wild fruits cultural domain of Debark and Adiarkay composed of 23 and 26 species, respectively. Kurar and Debir, in this order, recorded the longest (28 species) and shortest (11 species) citation of wild fruit species in their cultural domains at site level analysis.

\section{Intra-and inter-site species familiarity variations of informants}

In a free-list exercise, the differences in list length and content are measures of intra-cultural variation where individuals who know much about a subject list more terms than people who know less (Quinlan 2005). In view of this, the present study ratifies that knowledge of species among informants is heterogeneous where the majority of informants had less competence about wild fruit species that might be related to various factors.

Knowledge is generated and transmitted through interactions within specific social and agro-ecological contexts. Hence, ethnobiological knowledge and practice within any culture has been reported to vary by factors such as geographical origin, ethnicity, religion, occupation, educational background, social status and relations, income class, age and gender (Gisella 2006, Pfeiffer \& Butz 2005, Setalaphruk \& Price 2007). Among the informant attributes hypothesized to influence familiarity or knowledge of edible species using free-list length as a proxy, in the present study only the age of informants had a highly significant negative influence. Youngsters, especially children in the teens, appeared more knowledgeable than elders (Table 2). Those informants at and under the median age of 40 were more knowledgeable than those above. As demonstrated by the contingency table in Table 3 while $43.6 \%$ of those below the median age category cited 10 or more species (about mean value), the corresponding figure for those of above median age was only $8.1 \%\left(X^{2}=13.5\right.$; $\mathrm{P}<0.01$ ). This is consistent with other studies (Setalaphruk \& Price 2007, Styger et al. 1999, Tigist et al. 2006). There are several possible explanations for this. For instance, knowledge differences between adults and children might in part be due to differences in species preferences. Normally, adults keep away from eating most fruit species that are regarded as having high preference by children. As a result, it is possible that adults' free-lists would be limited to only those species which they consider to have utmost value to them than all the species they know. It might also be that driven by mounting food scarcity some species that were not known to be edible in earlier days are discovered by the young generation as edible. This is corroborated by the findings of Tigist et al. (2006) in Dheeraa area of Arsi, Ethiopia who found that fruits of the recently introduced Prosopis juliflora (Sw.) DC were liked by children while adults, perhaps because the species is new to them, keep distance from them.

The morphology and phenology of plant species and familiarity with the forest terrain were reported to determine the degree of use and knowledge about a species (Pardode-Santayana et al. 2007, Shrestha \& Dillon 2006, Wong et al. 2002). In the context of the present study, therefore, it is not surprising that children who have direct and regular contact to the forest and natural landscape and hands-on experience in gathering could recollect many edible species. While their intimate associations with the landscape gives them a chance for ecological literacy and perpetuates knowledge of edible species, it also provides them a chance to continually experiment and add more species to their own menus from time to time.

In addition, the fact that children have a wider knowledge acquisition routes than adults might explain the greater familiarity of wild fruit species by the former than the later. Children, apart from parental transmission and direct interaction with the natural environment, have a chance to broaden their wild fruit species vocabulary through horizontal contacts with their peers when performing various chores like herding, wood and fruit collection, hunting, schooling, water fetching and playing. In this respect, Setalaphruk and Price (2007) reported that the peer group is a crucial channel of knowledge acquisition for children.

However, knowledge differences between informants of different sites could be explained by other broader factors; such as differences in access and type of natural vegetation, which is in turn dictated by the level of anthropogenic intervention and climate of the area. Apparently, informants located far away from forests and dominated by the town milieu, like Debir and Adiaregay sites, tend to be familiar with relatively fewer species than those close to remnant forests (at Bermariam and Dibbahir) who were able to mention several species. This concurs with Van Den Eynden et al. (2003). As suggested by Guinand and Dechassa (2000), it may also very well be that in the semiarid areas, like in Adiaregay and Bermariam, where food is scarce people have been able to discover a greater variety of comestible species. Whereas, in the highly populated highlands, as in Debir site, where intensive cultiva- 

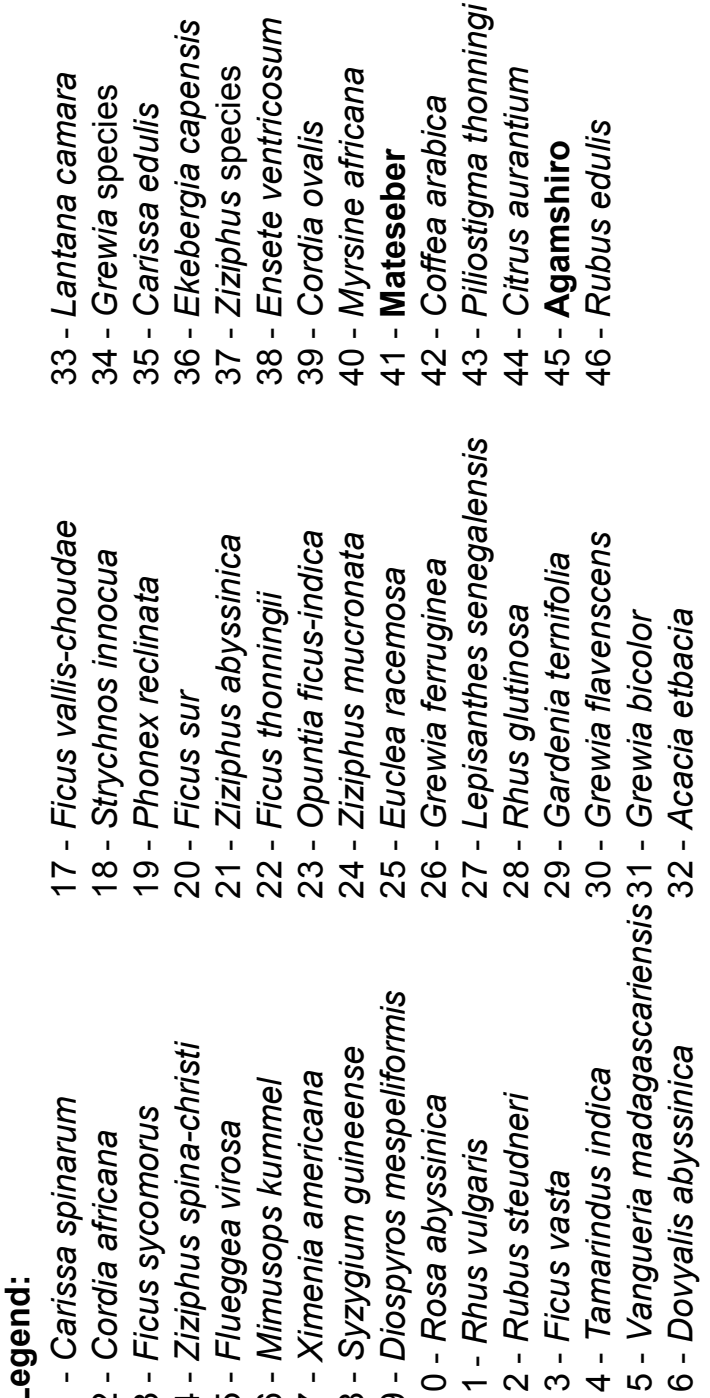

J
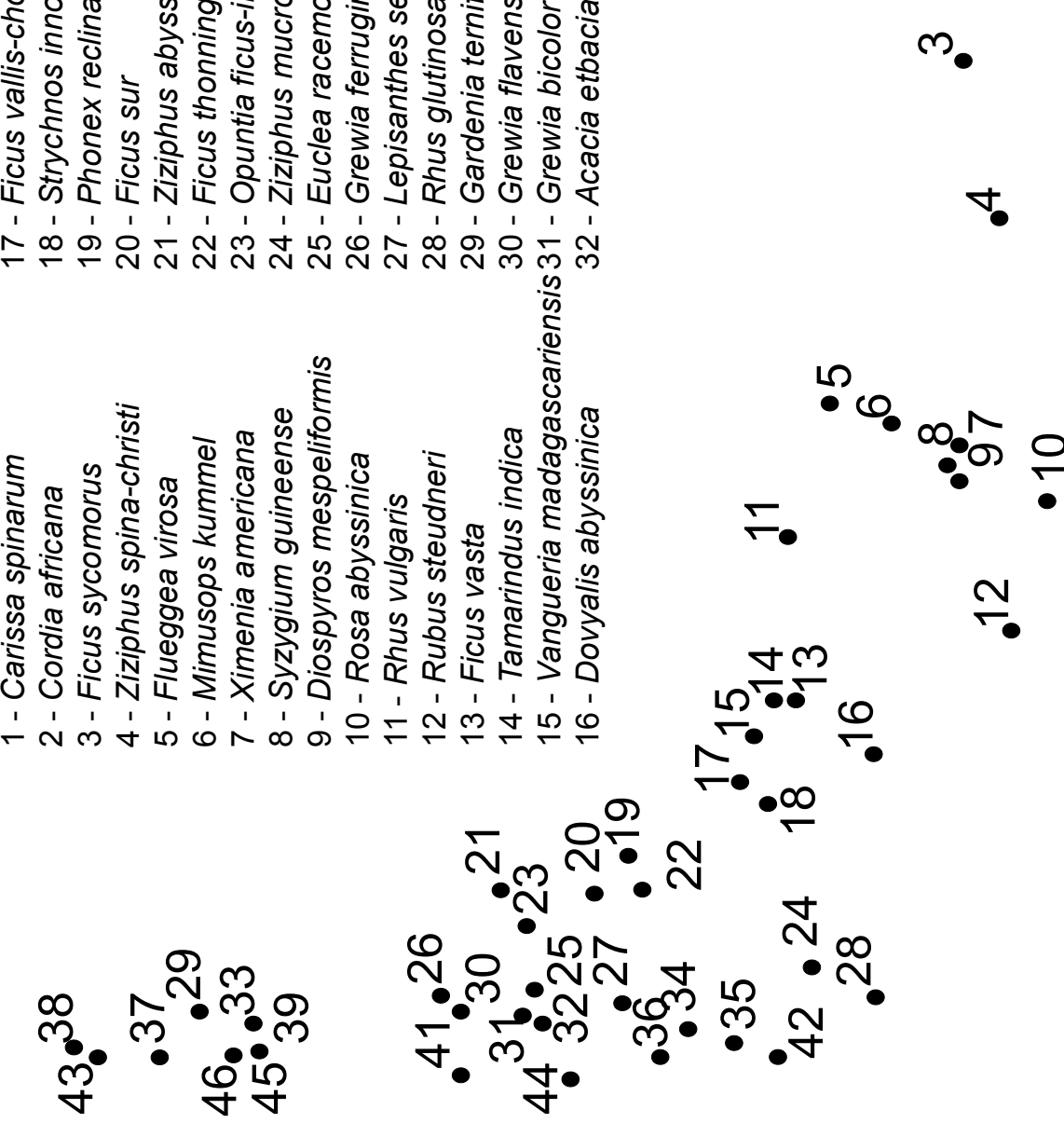
Table 1. Smith's $S$ index scores for different species of the five study sites.

\begin{tabular}{|c|c|c|c|c|c|}
\hline Species & Adiaregay & Bermariam & Debir & Dibbahir & Kurar \\
\hline Acacia etbaica & - & - & - & - & 0.19 \\
\hline Agamshiro & - & 0.02 & - & - & - \\
\hline Carissa edulis & - & - & - & - & 0.17 \\
\hline Carissa spinarum & 0.72 & 0.68 & 0.47 & 0.66 & - \\
\hline Citrus aurantium & - & - & - & 0.01 & - \\
\hline Coffea arabica & - & - & 0.01 & - & - \\
\hline Cordia africana & 0.46 & 0.63 & 0.28 & 0.73 & 0.33 \\
\hline Cordia ovalis & - & - & - & - & 0.07 \\
\hline Diospyros mespeliformis & 0.41 & 0.61 & - & 0.17 & - \\
\hline Dovyalis abyssinica & - & 0.03 & 0.4 & 0.1 & - \\
\hline Ekebergia capensis & - & - & - & - & 0.12 \\
\hline Ensete ventricosum & - & - & - & - & 0.01 \\
\hline Euclea racemosa & - & - & - & - & 0.21 \\
\hline Ficus sur & 0.04 & 0.05 & - & 0.01 & 0.38 \\
\hline Ficus sycomorus & 0.41 & 0.54 & 0.29 & 0.44 & 0.4 \\
\hline Ficus thonningi & 0.03 & 0.19 & - & - & - \\
\hline Ficus vallis-choudae & 0.15 & 0.1 & - & 0.06 & 0.35 \\
\hline Ficus vasta & 0.08 & 0.26 & - & 0.05 & 0.3 \\
\hline Flueggea virosa & 0.37 & 0.51 & - & 0.24 & 0.07 \\
\hline Gardenia ternifolia & - & 0.02 & - & - & 0.05 \\
\hline Grewia bicolor & - & - & - & - & 0.18 \\
\hline Grewia ferruginea & - & 0.01 & - & - & 0.15 \\
\hline Grewia flavescens & - & - & - & - & 0.16 \\
\hline Grewia sp & - & - & - & - & 0.23 \\
\hline Lantana camara & - & - & - & - & 0.07 \\
\hline Lepisanthes senegalensis & 0.02 & 0.09 & - & - & - \\
\hline Mateseber & - & 0.03 & - & - & - \\
\hline Mimusops kummel & 0.28 & 0.28 & - & 0.35 & 0.51 \\
\hline Myrsine africana & - & - & 0.05 & - & - \\
\hline Opuntia ficus-indica & - & - & 0.07 & 0.02 & 0.12 \\
\hline Phoenix reclinata & - & 0.08 & - & 0.18 & - \\
\hline Pliostigma thonningi & - & 0.02 & - & - & - \\
\hline Rhus glutinosa & - & - & - & - & 0.37 \\
\hline Rhus vulgaris & 0.19 & 0.34 & - & 0.23 & - \\
\hline Rosa abyssinica & - & - & 0.98 & 0.3 & 0.49 \\
\hline Rubus edulis & - & - & - & - & 0.02 \\
\hline Rubus steudneri & - & - & 0.68 & 0.3 & - \\
\hline Strychnos innocua & 0.08 & 0.23 & - & - & - \\
\hline Syzygium guineense & 0.16 & 0.19 & 0.12 & 0.79 & - \\
\hline Tamarindus indica & 0.09 & 0.09 & - & - & 0.83 \\
\hline
\end{tabular}




\begin{tabular}{|l|c|c|c|c|c|}
\hline Species & Adiaregay & Bermariam & Debir & Dibbahir & Kurar \\
\hline Vangueria madagascariensis & 0.12 & 0.16 & - & 0.15 & 0.21 \\
\hline Ximenia americana & 0.27 & 0.27 & - & 0.4 & 0.68 \\
\hline Ziziphus abyssinica & 0.04 & 0.11 & - & 0.04 & - \\
\hline Ziziphus mucronata & - & - & - & - & 0.52 \\
\hline Ziziphus species & - & - & - & - & 0.02 \\
\hline Ziziphus spina-christi & 0.71 & 0.7 & 0.18 & 0.21 & - \\
\hline
\end{tabular}

tion is the norm, biodiversity is considerably reduced and the possibility of finding wild-food plants has been minimized. As a result, informants would be able to find only a few species to recall during free-listing exercises.

In general, though wild fruits and perhaps the associated local knowledge are widely believed to be disappearing in several parts of Ethiopia, the present study proved this otherwise. It confirms the existence of a wealth of knowledge on a variety of wild fruit plants by the local community, especially the youth in the studied areas. The preservation of such knowledge is suggestive of the continued reliance of local communities on these resources (Kebu \& Fasil 2006). This is useful since, as Bell (1995) pointed out, the untold wealth of indigenous knowledge affords people the adaptability and resourcefulness that is so critical at times of stress, such as drought or crop failure, which is commonplace in the study areas and is likely to worsen in the event of swiftly changing climate. All told, the presence of greater knowledge of wild fruit species

Table 2. Relationships between informant attributes and free-list length ( ${ }^{*}$ Significant at $\mathrm{P}<0.001$; Dispersion parameter: 33.3; Deviance explained: $16.7 \%$ ).

\begin{tabular}{|c|c|c|c|}
\hline Attribute & Estimate & $\begin{array}{c}\text { Std. } \\
\text { Error }\end{array}$ & $\operatorname{Pr}>|\mathbf{z}|$ \\
\hline Intercept & 2.589 & 0.245 & $<2 \mathrm{e}^{-16 *}$ \\
\hline Age & -0.012 & 0.003 & $0.000^{*}$ \\
\hline Education & -0.083 & 0.083 & 0.319 \\
\hline Gender & 0.080 & 0.103 & 0.437 \\
\hline Language & -0.010 & 0.083 & 0.903 \\
\hline Religion & 0.079 & 0.133 & 0.552 \\
\hline
\end{tabular}

Table 3. A $2 \times 2$ contingency table on the relationships between age of informants and free-list length. (Pearson $\left.X^{2}=13.5, \mathrm{~S} . \mathrm{E}=0.08, \mathrm{P}<0.01\right)$.

\begin{tabular}{|c|c|c|c|}
\hline \multirow{2}{*}{$\begin{array}{c}\text { Free-list } \\
\text { length }\end{array}$} & \multicolumn{2}{|c|}{ Age of the informant (years) } & \multirow{2}{*}{ Total } \\
\cline { 2 - 3 } & $\mathbf{5 4 0}$ & $\mathbf{> 4 0}$ & \\
\hline$\leq 10$ & $31(56.4 \%)$ & $34(\mathbf{9 1 . 9 \% )}$ & 65 \\
\hline$>10$ & $24(\mathbf{4 3 . 6 \% )}$ & $3(8.1 \%)$ & 27 \\
\hline Total & 55 & 37 & 92 \\
\hline
\end{tabular}

especially on the part of the younger generation is a good signal for the perpetuation of indigenous knowledge.

\section{Species saliency}

In cultural domains, species are held in a structured manner with some having more importance than others; some are more prominent in the minds of the people that constitute the culture and some less obvious (Castaneda 2004). A salient species is one with high frequency of mention by informants, appearing early in their species listing (Martin 1995) and corresponding to a higher Smith's salience score to reflect the familiarity level of the species in the community. Plotting of free-list frequency against average rank of species for the entire study area domain is in order in Figure 2. As can clearly be seen, species such as Ensete ventricosum (Welw.) Cheesman and Piliostigma thonningii (Schumach. \& Thonn.) Milne-Redh. lying at the very top-left of the graph recorded a very low frequency and rank. Therefore, such species can be considered as the idiosyncratic views of individuals. At the bottom-left of the graph lies Myrsine africana L. with a very low frequency but relatively high rank indicating that if this species had a higher frequency it would have been cited early in the informants lists. At the extreme bottom-right appears

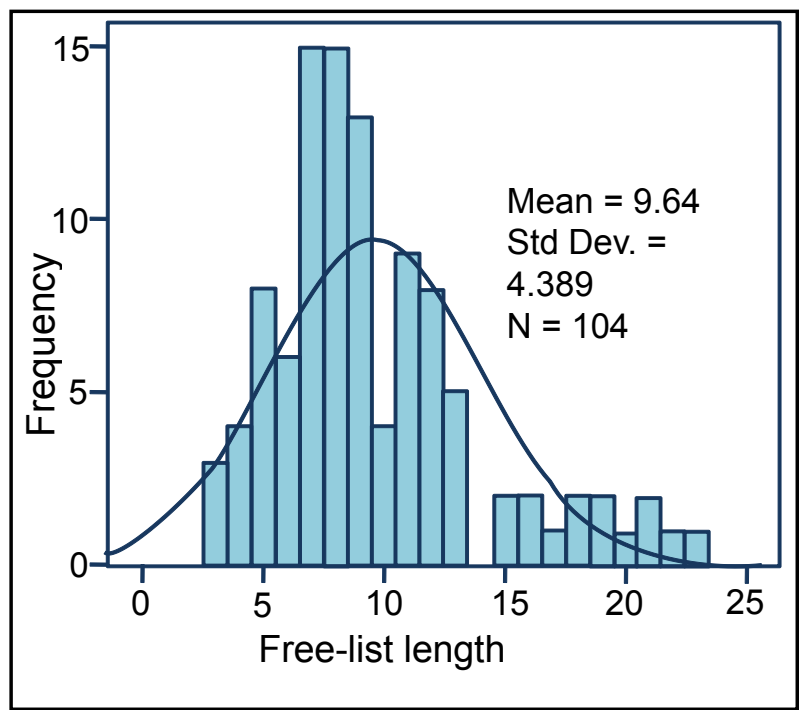

Figure 3. Informants knowledge of wild fruit species across sites $(\mathrm{N}=104)$. 
Carissa spinarum $\mathrm{L}$. with the highest frequency (82\%) and highest average rank (3.6) followed by species that recorded moderate frequency $(60-80 \%)$ and average rank (4th-5th rank) like Cordia africana Lam., Ficus sycomorus L. and Ziziphus spina-christi (L).Desf. Such a correlation between high rank and high frequency of these species signifies that they are the most significant to people. Estimates of average saliency of species were further judged by Smith's salience index scores (Table 1). Evidently, salience indices for the major part correspond to species frequency and average rank scores. Simply put, species of high frequency and average rank recorded a higher Smith's salience index while less-frequent and low-rank species recorded low salience index.

Examining such average psychological saliency of species helps to understand how the domain is perceived across a group of people (Sinha 2003). In total, the most salient species with informant frequency of $82 \%, 79 \%$, $74 \%, 63 \%$ and $50 \%$ in that order appear to be represented by C. spinarum, C. africana, F. sycomorus, Z. christi and Flueggea virosa (Willd.) Vigot. Hence, these species can be regarded as the most significant species to informants that translate into prototypical to wild fruits domain. In contrast, about $52 \%$ of the species had $10 \%$ or less informant frequency suggesting that they are less significant to informants.

Smith's salience index score for species of individual sites domain is given in Table 1. A typical domain is one that is characterized by a core set of items mentioned by many respondents and a large number of items cited by a few or just by one person (Borgatti 1996, Martin 1995). In the present case, slight variations are noticeable among sites, on those species of high saliency with respect to their number, type and degree of saliency. Apparently, the highest saliency index (0.98) for the most salience species was recorded at Debir for Rosa abyssinica $\mathrm{R}$. Br. while the lowest $(0.70)$ was at Bermariam for Z christi. This might be related to the weight given by informants to the species regarded most salient in respective sites relative to runner up salient species. Consequently, in sites where there appear several salient species of comparable significance the relative weight given to the most salient species would be lower. This is because people will have several choices to make for the species that is put in the front in their freelists that eventually results in less informant agreement and thus overall lower salience score.

On the other hand, the degree of species saliency was noted to be slightly changing by the scale (stratum) of cultural domain analysis at study area, district or site levels. For instance, while $R$. abyssinica was the most salient species in Debark at the district level analysis, its degree of saliency changed merely to medium level when the data is aggregated to the highest strata (study area level). Similarly, the saliency of Syzygium guineense (Willd.) DC that was recorded to be very high at site level in Dib- bahir appears to be much underestimated at the district level analysis. The results brought to light that, because of the significant differences in the type and importance of species among the different sites, assessment of cultural domain at a higher scale (aggregated data at study area and district level) than a lower scale (site level) is very likely to masquerade and undermine the knowledge, interests and preferences of the local community at respective sites. However, scale of analysis did not have a significant influence on degree of saliency of some species like $C$. spinarum. This might be explained by the wide ecological distribution as well as the degree of importance of the species that would result in greater familiarity by informants across locations.

\section{Similarities and differences among cultural domains of sites}

Each locality is bestowed with a wide range of wild fruit species some of which are pretty important in one locality but hardly known or virtually inedible in another. The dendrogram in Figure 4 portrays similarities among sites in terms of wild fruits cultural domain. Taking $10.5 \%$ dissimilarity coefficient as a cut-off point, three sites, namely Adiaregay, Bermariam and Dibbahir showed great resemblance with respect to fruit species that make up their domains. These same sites also share similar species of high salience scores (C. spinarum and Z. christi). Climatic similarity that shapes the types of species occurring and in turn results in a shared culture among people of these adjacent sites could be a large part of the explanation. On the other hand, characterized respectively by very cool and arid climates the wild fruit species cultural domains of Debir and Kurar sites appear to be different from all other sites and from each other. It might as well be that $\mathrm{Ku}$ rar being a more isolated site, a lack of information sharing and thus differences in culture may account for its peculiarity. The higher cultural domain dissimilarity among sites finds further evidence from the fact that the five sites have only two species, $F$. sycomorous and C. africana, in common. Pagella et al. (2002) suggested that while knowledge differs to some extent between communities, common frameworks and terminology may occur across large distances and people with similar agro-ecological circumstances in different geographical and cultural contexts may have similar perceptions. In the context of the present study, therefore, familiarity of people with some species across sites however few reflects, apart from sitespecific knowledge, the existence of a shared knowledge among communities of different sites.

\section{Species co-occurrence in free-lists}

In cultural domain analysis, there appears a relation between species in free-lists in terms of how people think of them that gives the domain a structure. Such is portrayed in Figure 5 by a non-metric two-dimensional scaling map of wild fruits domain of Debark district that yielded a clear 


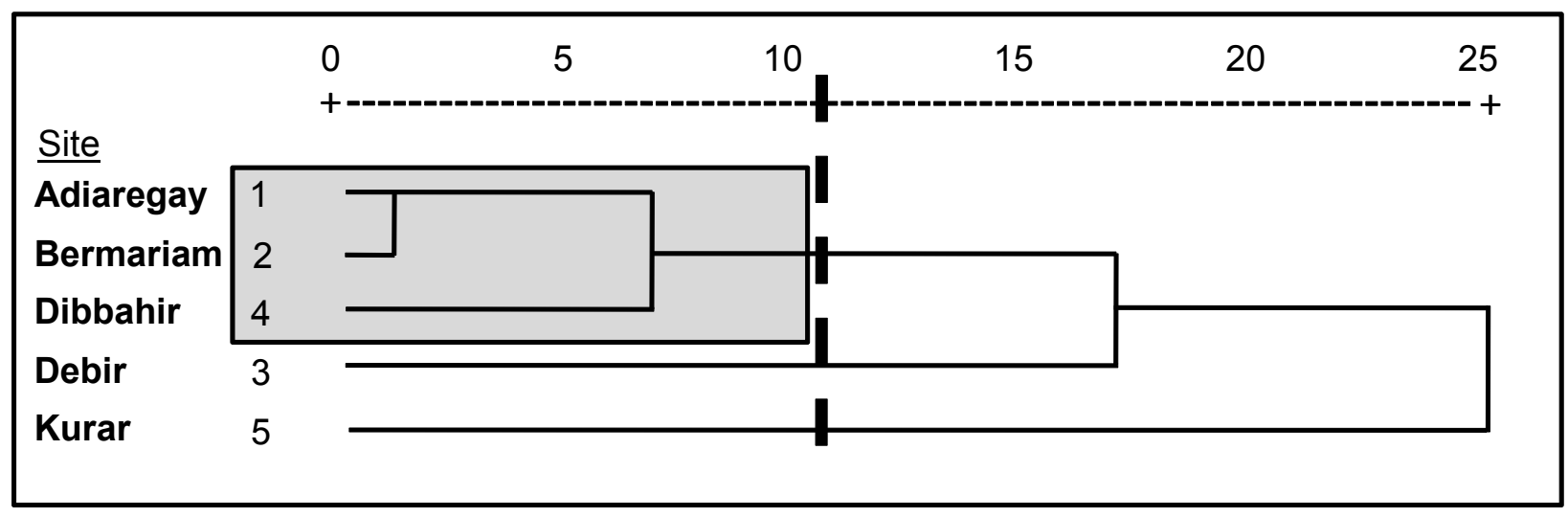

Figure 4. A dendrogram showing classification of informants of different sites in three districts of Amhara region, Ethiopia based on similarities in free-lists of wild edible fruit species (Bray-Curtis distanced average linkage hierarchical agglomerative algorithm). The cut off point is set at $10.5 \%$.

insight into the relation among the species as well as their level of importance. Distance within the map represents the degree of similarity amongst species in terms of being mentioned more often and together by informants

while distance from the center of the map gives a hint about the importance of each species within the domain (Castaneda 2004). Species in the map appeared more or less in what is commonly termed as fried egg fashion,

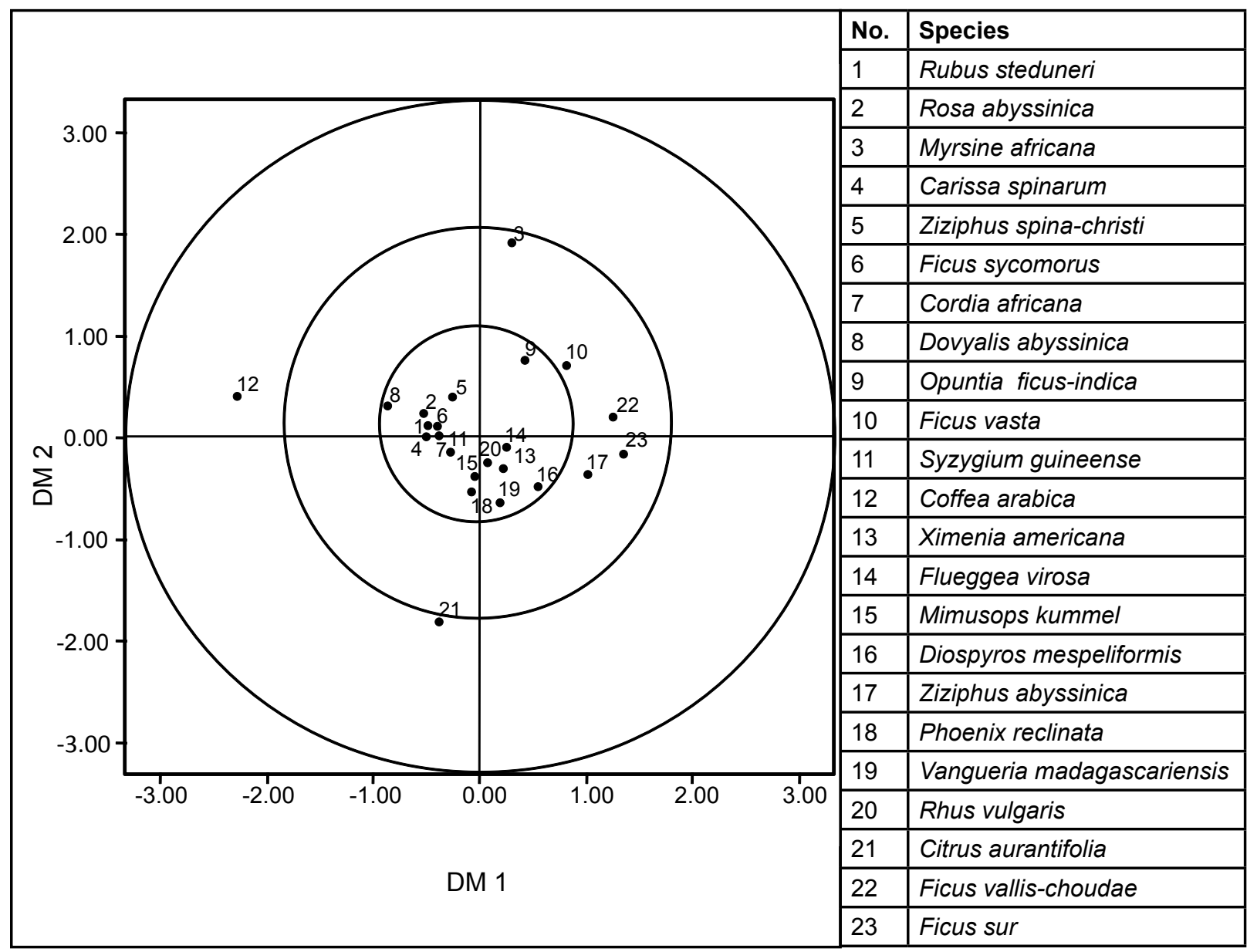

Figure 5. A non-metric two-dimensional scaling (NMDS) map of wild fruits species domain at Debark, Ethiopia (Stress in two dimensions is 0.99). 
where the most salient species of the domain are clustered in the inner core, the less frequent and less important species in the second circle and species mentioned rarely as outliers in the outermost circle. Consequently, the innermost circle of the map composed of 16 species that includes, among others, R. abyssinica, C. spinarum, Rubus steudneri Schweinf. and $C$. africana, which are most frequently quoted edibles. Particularly, $R$. abyssinica and $R$. steudneri (clustered in the first iteration at $82 \%$ similarities in the tree diagram not shown) and $C$. africana and $F$. sycomorus (second iteration at $79 \%$ similarities) appear to be species that are most frequently and consistently mentioned together. The middle circle is occupied by five species; namely, Ficus vasta Forssk, Ficus vallischoudae Delile, M. africana, Opuntia ficus-indica (L.) Mill. and Ziziphus abyssinica Hochst. ex A. Rich. that are for most part regarded as delicacies only for children. The outermost circle consists of two outlier species (Coffea arabica L. and Citrus aurantium L.) that were cited by two informants each. The later species are popular domesticates, that occur only rarely in a wild state and they happen to be known only to a few people in the wilderness so that their frequency is very low. Therefore, these species are rather less important as only a few individuals hold the knowledge about them (Castaneda 2004). Moreover, an interesting pattern emerged in the two-dimensional scaling map such that respondents of the same site showed a tendency to name similar species that occur very closely together. Within such sub-groups the more salient species form a cluster of their own. Accordingly, most species in the second quadrant are those cited by informants from Debir site while the third and fourth quadrants are occupied by species cited by Dibbahir informants. This concurs with Tigist et al. (2006), and apparently shows a shared culture among informants within than between sites.

Grouping tendency of fruit species was further illustrated by a cluster analysis of free-lists of Adiarkay District, as an example (Figure 6). In this case, at $10.5 \%$ cut-off point two clusters were apparent. The larger cluster consists of seven species: C. spinarum, Z. spina-christi, $C$. africana, F. sycomorus, Diospyros mespiliformis Hochst. ex. A. DC, F. virosa and Rhus vulgaris Meikle. This list perfectly corresponds to the highly salient species of the
Piliostigma thonningi Grewia ferruginea

Agamshiro

Dovyalis abyssinica

Gardenia ternifolia

Mateseber

Carissa spinarum

Ziziphus spina-christi

Diospyros mespeliformis

Cordia africana

Ficus sycomorus

Flueggea virosa

Rhus vulgaris

Mimosops kummel

Ximenia americana

Ficus vallis-choudae

Syzygium guineense

Zizyphus abyssinica

Tamarindus indica

Ficus vasta

Ficus thonningii

Vangueria madagascariensis 1

Strycnos innocua

Lepisanthes senegalensis

Phoenix reclinata

Ficus sur

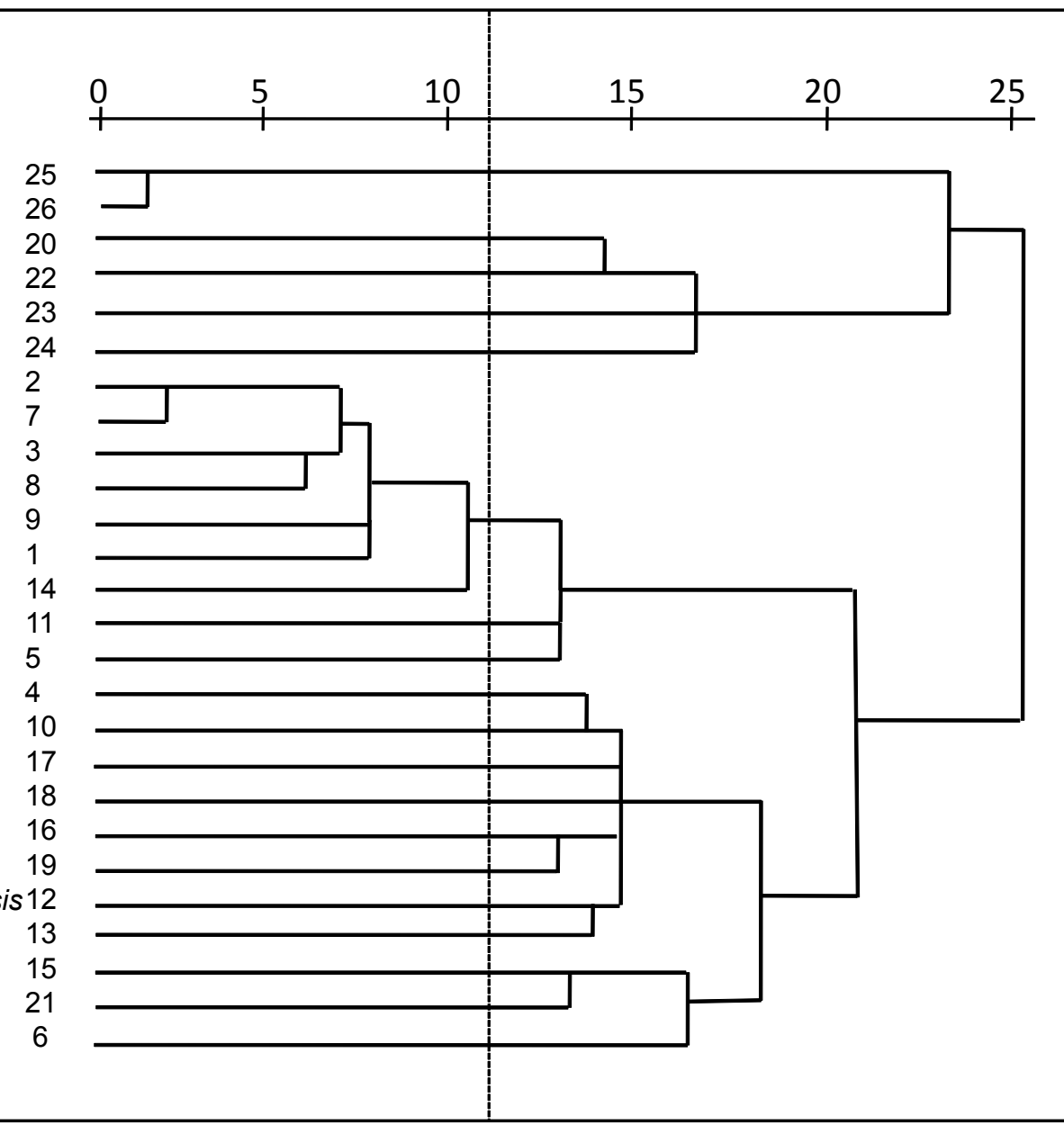

Figure 6. A dendrogram depicting clustering of species in free-lists of Adiarkay district wild fruits domain (Bray-Curtis distanced average linkage hierarchical agglomerative algorithm). The cut off point is set at $10.5 \%$. 
district's wild fruits domain. Out of these, by being joined in the second iteration (14\% dissimilarity coefficient), $C$. spinarum and $Z$. spina-christi tend to be frequently mentioned together. The second cluster was formed out of two infrequently mentioned species, $P$. thonningii and $G$. ferruguinea that were again consistently mentioned together. Likewise, cluster analysis of species at study area and site levels (not shown) followed a similar trend.

\section{Informant consensus}

Consensus analysis provides a framework and method of analyzing patterns of agreement among respondents and a way to uncover the culturally correct answers to a set of questions in the face of certain kinds of intra-cultural variability. As such, it enables the assessment of the extent of knowledge possessed by each informant about the cultural domain (Borgatti 1994, 1996, 1997, Quinlan 2005). In the present study, the estimated knowledge of informants (typicality), which is the percentage of agreement of their list to the model list, varied among informants within and between localities (Table 4). Informants at Debir had a higher mean estimated knowledge of $0.61 \pm 0.26$ whereas Kurar recorded very low, $0.10 \pm 0.43$ indicating that informants are very diverse in the latter and poorly represent the community they were drawn from.

As a rule, the higher the frequency score the more normal the informant is considered. Consequently, informants who score a value close to "one" will have a higher cultural competence and represent the community well, and in the event of complete consensus every one would score "one". On the other hand, low score value means that informants do not follow the norm, which is often explained by the loss of knowledge or expert knowledge or a different culture, or misunderstanding the free-list task (Puri \& Vogl 2005). For example, a teenage cattle herder boy who reported 23 species in his free-list at Adiarkay recorded the lowest knowledge score (0.03) and appeared an outlier. However, this can be accounted for as his exceptionally high competence. Certainly, his day after day intimate association with the forest and heath gives him a chance of exploring all possible niches and familiarizing himself with several edible species.

As demonstrated in Table 4, high pseudo-reliability values in all sites but Kurar implies that informants have a higher consensus in their respective consensus keys. This together with the factor loadings in eigenvalues table suggests that informants are drawn from a single culture in their own respective localities. Hence, the variations in respondents' answers are unsystematic that arose simply from variance in cultural centrality (Borgatti 1994, 1997). Conversely, Kurar recorded a relatively lower pseudo-reliability (0.61) and the first factor of the eigenvalues explained only $40.3 \%$ of the variation. This signifies the existence of great variability among informants' knowledge and thus violation of a one-culture assumption. Indeed, a closer look at the Kurar site data has shown that the age of informants is responsible for these variations, where young and adult informants provided different sets and lengths of species in their free-lists. Importantly, however, this variability might also arise from the small sample size (Sinha 2003). As a result, informants at Kurar appear to have a lower consensus.

Overall, in all sites there appeared a great overlap between species included in the consensus model and those with high salience index scores. More often than not, these are the species that many people share or are familiar with most. Moreover, it was noted that the higher the scale of analysis the lower the number of species are included in the consensus model. As a result, only four species, in order of importance, $C$. spinarum, Z. christi, $C$. africana and $F$. sycomorus attained a study area level informant consensus (Table 4). Such a low level of informant agreement is suggestive of the high variability among informants of the different sites. Hence, as cautioned by Borgatti (1994), attempts to aggregate data from across all informants of different sites, which are of distinct sub-culture, to obtain a majority view will be a futile exercise.

\section{Species preference}

The present study confirmed that each locality has its own set of favorite species. Generally, Z. spina-christi with $28.6 \%$ informant frequency followed closely by $C$. spinarum and D. mespilliformis at par (23.8\%) appear to be species of high preference in Adiarkay while at Debark $R$. abyssinica (37.5\%) and S. guineense (29.2\%) are most valued species (Figure 7). At Kurar site of Dejen district, Tamarindus indica L. (80\%) and Ximenia americana L. (20\%) were species of utmost preference. Species preference was reported to vary among different areas and communities depending on species distribution, indigenous knowledge and economic pursuits of the community (Pauline \& Linus 2004). In the context of this study, variations in species preferences among sites, especially between Debir (less species rich site) and the other four sites are likely to arise from differences in species distribution intensity because of the wide array of ecological niches at short distances. This would in turn bring about cultural differences among informants of different sites.

Nevertheless, even close-by sites were not immune to variations in species preference of people as can be seen between Adiaregay and Bermariam sites. While these sites are adjacent to each other and share similar climate as well as a more or less similar flora, perhaps because of influence from language and culture of the neighborhood Tigryan people on Adiaregay informants, informants' species choice as well as vernaculars tend to be slightly different from Bermariam. The overriding influence of culture on species choice can also clearly be demonstrated by $T$. indica and $X$. americana species. While these species occur both at Kurar and at Adiarkay localities, they were rat- 


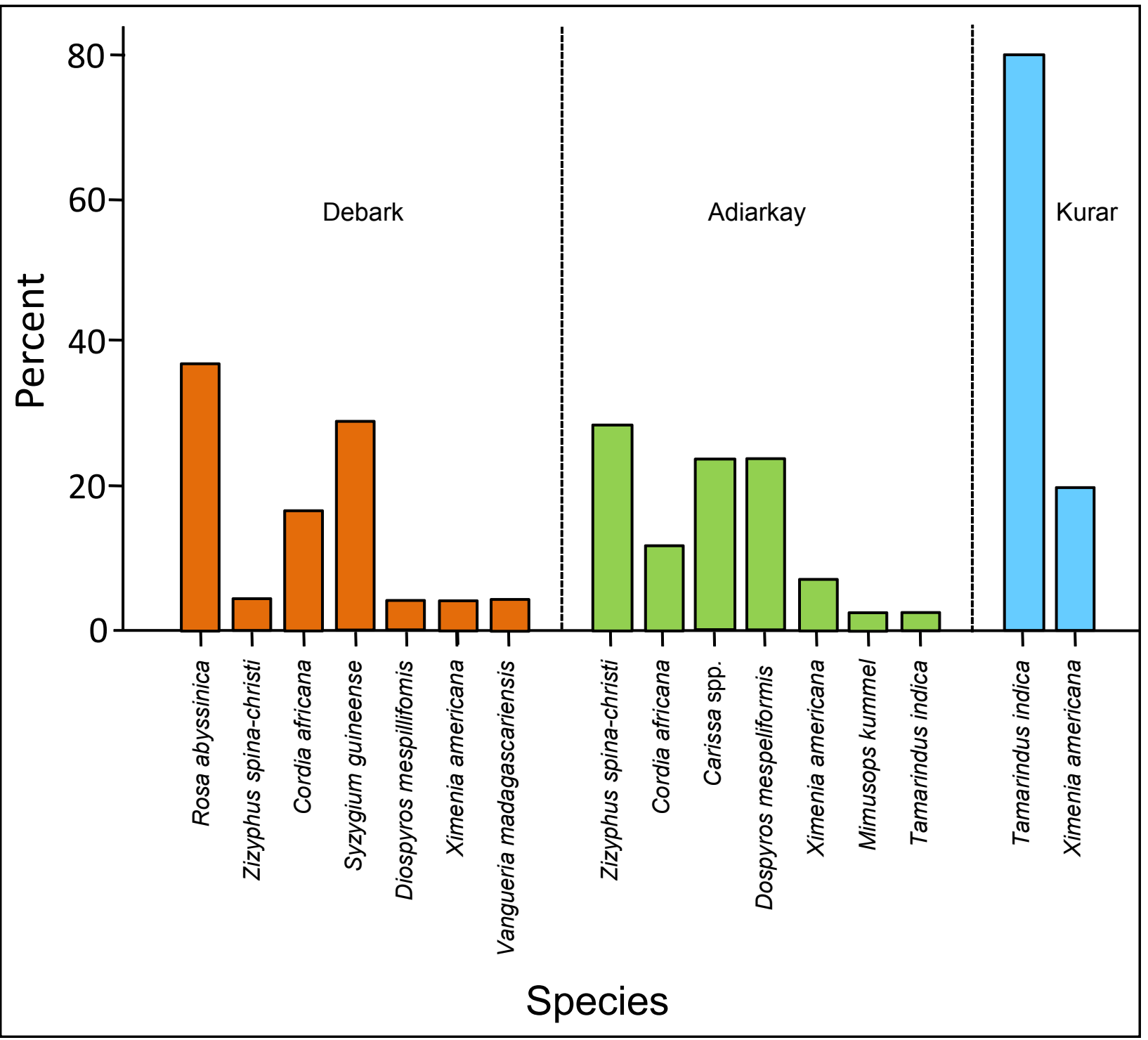

Figure 7. Wild fruit species preferences at Adiarkay $(\mathrm{N}=42)$, Debark $(\mathrm{N}=21)$ and Kurar $(\mathrm{N}=20)$ in Amhara region, Ethiopia based on summaries from individual interview responses.

ed differently at the two sites; very high at the former and were low at the latter. Generally, the findings suggest that species preference tends to be more dependent on sociocultural factors rather than biological such as climate or availability of the species in the locality.

Moreover, like the case of cultural domain analysis species preferences of people were noted to slightly undervalued, if not on the type, in the rank order of priorities, when data was analyzed at higher (total study area and district) than lower scale (site). For instance, R. abyssinica and $S$. guineense, in this order, appeared the most sought-after species in the aggregated data of Debark district. However, a site level analysis revealed that these species rank the best in their respective sites: $R$. abyssinica at Debir and S. guineense at Dibbahir. This indicates that district level prioritization has somehow underrated species preferences of Dibbahir informants.

In addition, species preferences tend to slightly varying by age. Adults were found to perceive the value of wild fruit bearing plant species stereotypically for their non-fruit utilities than fruits while the reverse was true on the part of children. Therefore, the confounding variable of non-fruit utility perspective implicitly held by the adult age group is bound to influence fruit species ranking exercises. Furthermore, precedence of non-fruit services to fruits by elderly could be a cause for concern as it can have grave implications in the sense that since in most cases adults are the decision makers of the family wild fruit species will most likely be exploited for non-fruit utilities than fruits. 


\begin{tabular}{|c|c|c|c|c|c|c|c|c|}
\hline 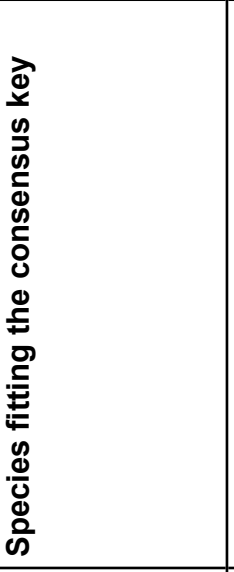 & 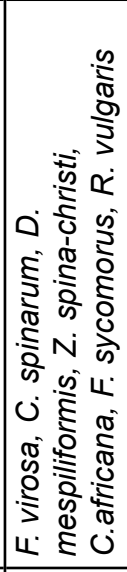 & 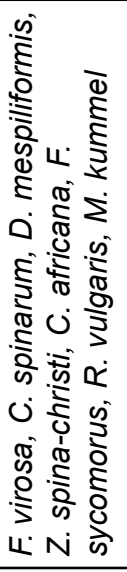 & 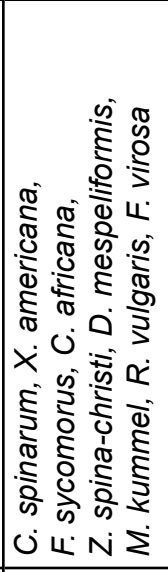 & 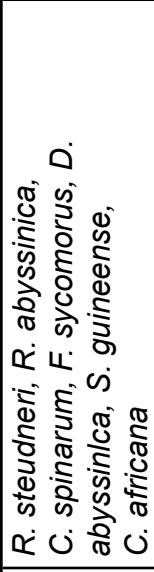 & 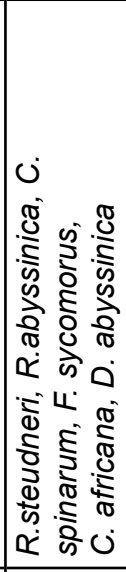 & 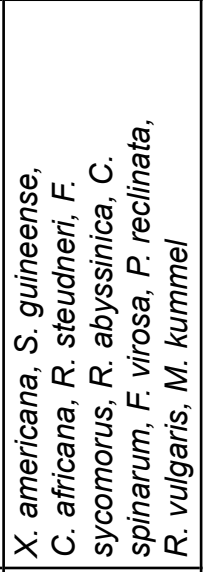 & 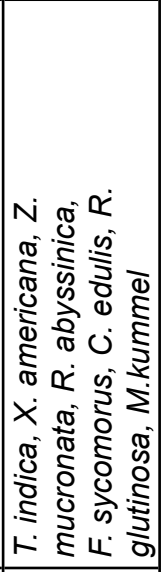 & 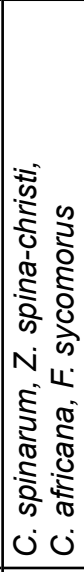 \\
\hline 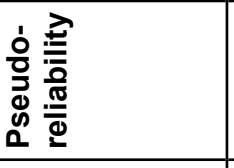 & $\stackrel{\circ}{\circ}$ & ه্ & ه্ & $\stackrel{\circ}{-}$ & O্ & ه্ & $\begin{array}{l}\infty \\
0 \\
0\end{array}$ & $\stackrel{\circ}{-}$ \\
\hline 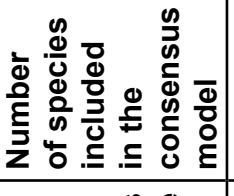 & & $\infty$ & $\sigma$ & $\wedge$ & 0 & $\mp$ & $\infty$ & $\nabla$ \\
\hline 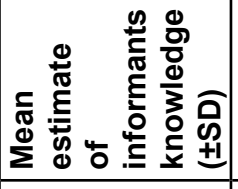 & 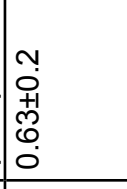 & $\begin{array}{l}n \\
\\
+1 \\
10 \\
0 \\
0 \\
0\end{array}$ & $\mid \begin{array}{l}\stackrel{N}{N} \\
0 \\
o+1 \\
0 \\
0 \\
0 \\
0 \\
\end{array}$ & $\begin{array}{l}\stackrel{1}{N} \\
0 \\
+1 \\
⿱ 1 \\
0 \\
0 \\
0\end{array}$ & $\begin{array}{l}0 \\
N \\
0 \\
+1 \\
\vdots \\
\vdots \\
0 \\
\end{array}$ & $\begin{array}{l}1 \\
\therefore \\
0 \\
+1 \\
0 \\
0 \\
0 \\
0 \\
0\end{array}$ & 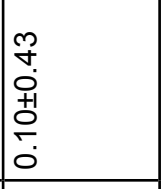 & \begin{tabular}{l}
0 \\
\hdashline \\
0 \\
+1 \\
0 \\
0 \\
0 \\
\end{tabular} \\
\hline 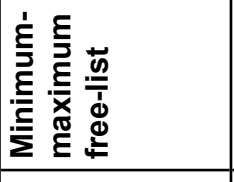 & 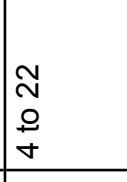 & $\begin{array}{l}\underset{1}{2} \\
\stackrel{+}{+} \\
+\end{array}$ & $\begin{array}{l}\mathbb{N} \\
0 \\
i \\
10 \\
\end{array}$ & $\begin{array}{l}\text { N } \\
\text { Oे } \\
\text { ஸे }\end{array}$ & $\begin{array}{l}\infty \\
0 \\
0 \\
\end{array}$ & $\begin{array}{l}\stackrel{D}{N} \\
0 \\
i \\
0 \\
\end{array}$ & $\begin{array}{l}N \\
N \\
0 \\
10 \\
L\end{array}$ & $\begin{array}{l}\text { N } \\
\stackrel{2}{\text { m }} \\
\end{array}$ \\
\hline 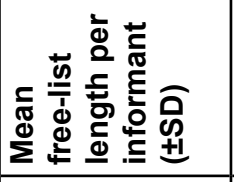 & 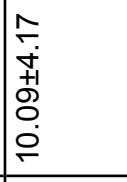 & 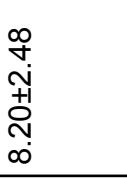 & 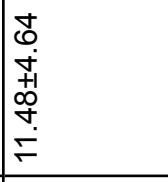 & $\begin{array}{l}m \\
m \\
m \\
+1 \\
+1 \\
0 \\
\infty \\
\infty\end{array}$ & 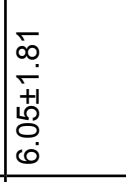 & \begin{tabular}{l}
\multirow{2}{*}{} \\
$\tilde{m}$ \\
+1 \\
$\infty$ \\
$\infty$ \\
$\infty$ \\
\end{tabular} & 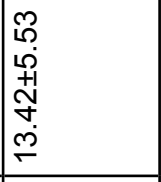 & 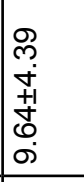 \\
\hline 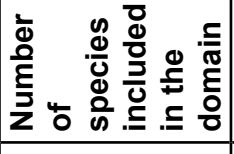 & $\stackrel{N}{N}$ & $\stackrel{\circ}{\longrightarrow}$ & $\stackrel{\leftrightarrow}{\sim}$ & $\stackrel{\sim}{\sim}$ & $\mp$ & $\bar{N}$ & $\stackrel{\infty}{\sim}$ & $\stackrel{\rho}{+}$ \\
\hline 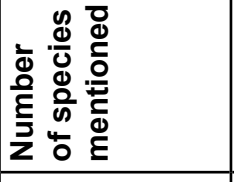 & $\bar{m}$ & $\bar{N}$ & $\stackrel{\text { N }}{\text { s }}$ & $\bar{m}$ & $\stackrel{m}{\sim}$ & $\stackrel{\infty}{\sim}$ & $\stackrel{\infty}{\sim}$ & กิ \\
\hline 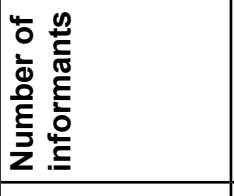 & 守 & $\stackrel{\text { }}{ }$ & $\hat{\sim}$ & $\stackrel{L}{+}$ & N & 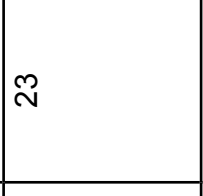 & $\cong$ & 음 \\
\hline 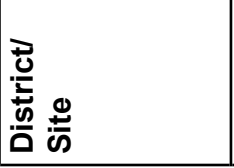 & 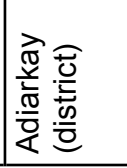 & 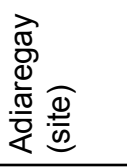 & 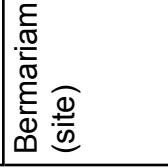 & 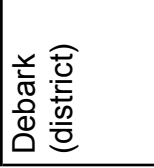 & 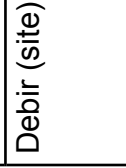 & 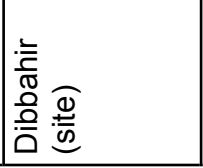 & 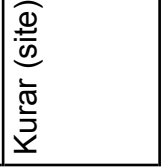 & 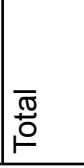 \\
\hline
\end{tabular}


Overall, there is a clear preference for $Z$. spina-christi, R. abyssinica, Carissa species, D. mespiliformis, $S$. guineense, T. indica, Mimusops kummel Bruce ex A. DC., Dovyalis abyssinica Warb. and $X$. americana in the study area. Interestingly, except $D$. abyssinica these species are in commerce in their respective localities. This criterion might have been considered during informants' preference ratings. More appealing was that the most preferred species largely match the highly salient species identified in the cultural domains of respective localities. This might suggest that free-listing technique can effectively be used to reinforce species prioritizing methods like pairwise ranking to generate species preference lists of people. Generally, peoples' high inclination to the above species coupled with the high consensus and saliency score records suggest that they merit consideration for wider promotion and use. For example, $M$. kummel fits with the country's priority list (Demel \& Abeje 2004), while Ziziphus and Tamarind are within Biodiversity International's priority species in Eastern and Southern Africa (IPGRI 2002). Hence, there is a good prospect and opportunity for promoting these species making use of knowledge and experience from collaborative research.

\section{Conclusion}

The study provided an interesting insight into the cultural domain of wild fruit species at varying scales of analysis: total study area, district and site, including species of high prominence and preference to the people. Notwithstanding the marginal environment, the wild fruits domain of the study area appeared fairly rich. However, despite the enormous language, ethnicity and religion sharing among people of the different sites, each locality appeared to have its own peculiar domain and salient species with some level of species sharing with others. Such a scenario is instructive in that an attempt to solicit a cultural domain of wild fruits and people' species preferences by aggregating the data to a study area level underestimates the cultural domains of districts and sites and would fall short of articulating perceptions and preferences of informants.

Among personal attributes age appears to be the single most important factor responsible for knowledge variations of wild fruit species where youngsters are more knowledgeable than elders. This wealth of genius of wild fruits on the part of the younger generation is suggestive of the sustainability of indigenous knowledge. In addition, apart from cultural differences, rich floral backdrop of a locality, proximity to natural vegetation and closer association with the landscape as well as geographical isolation are some of the factors that explain variations in informant's wild fruit knowledge. The findings further revealed that species that appear highly salient for the most part overlap with highly preferred species. This points out that during free-listing exercises informants give precedence to favorite species, which suggests the possibility of employing the free-list technique to reinforce species prioritizing activities.
In total, as the cultural domain analysis and species preference results suggest, $Z$. spina-christi, $C$. spinarum and D. mespilliformis at Adiarkay, R. abyssinica, C. spinarum and $S$. guineense at Debark and $T$. indica and $X$. americana at Kurar appear as the most important species of high fervor by the community, which will possibly translate into their increased usage and conservation. In general, future contemplations on the wild fruits of the study area might need to keep fruit species of high consensus to the forefront and and make use of those informants identified as having high species competence.

\section{Acknowledgements}

We are very grateful to Austrian Exchange Service (Österreichischer Austauschdienst) for financing this research through offering a $\mathrm{PhD}$ scholarship opportunity for the first author. Our great thanks also go to the Amhara Regional Agricultural Research Institute for giving him a PhD study opportunity, and to the Institute of Forest Ecology of Boku University for hosting him during his study. We give special thanks to the farmers for sharing us their wealth of knowledge and spending their precious time with us. We are also indebted to the two anonymous reviewers who provided us with invaluable comments.

\section{Literature Cited}

Albuquerque, U.P. \& R.F. Oliveira 2007. Is the use-impact on native caatinga species in Brazil reduced by the high species richness of medicinal plants? Journal of Ethnopharmacology 113(1):156-170.

Bell, J. 1995. The Hidden Harvest. Seedling October. www.grain.org/seedling/?id=157.

Borgatti, S.P. 1992. ANTHROPAC 4.983/X. Analytic Technologies. Columbia, SC.

Borgatti, S.P. 1994. Cultural Domain analysis. Journal of Quantitative Anthropology 4:261- 278.

Borgatti, S.P. 1996. ANTHROPAC 4.0 Methods guide. Analytic Technologies Natick, MA.

Borgatti, S.P. 1997. Consensus Analysis. www.analytictech.com/borgatti/consensu.htm (accessed January 2008).

Bureau of Planning and Economic Development (BoPED). 1999. Atlas of Amhara National Regional State. Bahir Dar, Ethiopia.

Castaneda, H.C. 2004. Ethnobotanical Analysis of Different Successional Stages as Sources of Wild Edible Plants for the Guaymi People in Costa Rica. PhD Dissertation, University of Florida. 
Castaneda, H. \& J.R. Stepp. 2007. Ethnoecological Importance Value (EIV) methodology: Assessing the cultural importance of ecosystems as sources of useful plants for the Guaymi people of Costa Rica. Ethnobotany Research \& Applications 5:249-257.

DeJordy, R., S.P. Borgatti, C. Roussin \& D.S. Halgin. 2007. Visualizing Proximity Data. Field Methods 19(3): 239-263.

Demel T \& E. Abeje. 2004. Status of indigenous fruits in Ethiopia. Review and Appraisal on the Status of Indigenous Fruits in Eastern Africa. A synthesis report for IPGRISAFORGEN. www.bioversityinternational.org. Edited by Chikamai, B., O. Eyog-Matig \& D. Kweka.(accessed December 2007).

Edwards, S. 1992. Traditional Tree Crops in Ethiopia: Historical records and economic importance. Pp 10-13 in Proceedings of the second Natural Resources Conservation Conference. Institute of Agricultural Research, Natural Resources Management for conservation and development, Addis Ababa.

Getachew, A., U. Kelbessa \& D. Dawit. 2005. Ethnobotanical study of edible indigenous plants in some selected districts of Ethiopia. Human Ecology 33(1):83118.

Getahun, A. 1974. The role of wild plants in the native diet in Ethiopia. Agro-Ecosystems 1:45-56.

Gisella, S.C.G. 2006. The mother-child nexus. Knowledge and valuation of wild food plants in Wayanad, Western Ghats, India. Journal of Ethnobiology and Ethnomedicine 2:39.

Grivetti, L. E. \& B. M. Ogle. 2000. Value of traditional foods in meeting macro and micronutrients needs: The wild plant connection. Nutrition Research Reviews 13:31-46.

Guinand, Y. \& L. Dechassa. 2000. Indigenous food plants in southern Ethiopia: Reflections on the role of 'famine foods' at the time of drought. Pp 31-45 in The Potential of Indigenous Wild Foods. Workshop Proceedings. http:// pdf.usaid.gov/pdf_docs/Pnacl441.pdf United Nations Emergency Unit for Ethiopia Survey, Addis Ababa.

International Plant Genetic Resources Institute (IPGRI). 2002. Neglected and Underutilized Plant Species: Strategic Action Plan of the International Plant Genetic Resources Institute. IPGRI. Rome, Italy.

Kebu B. \& K. Fassil. 2006. Ethnobotanical study of indigenous edible plants in Derashe and Kucha Districts, South Ethiopia. Journal of Ethnobiology and Ethnomedicine 2:53.
Khanh, T. C., T.V. On, D.D. Tien, T. Cu, P.S.W. Jackson \&. F. Dennis. 1999. Establishment of a Botanic Garden for the Protection of the Plant Genetic Resources of the Tam Dao National Park, Vietnam. www.bgci.org/congress/congress_1998_cape/html/home.htm (accessed December 2007).

Lykke, A.M. 1998. Assessment of species composition change in savanna vegetation by means of woody plants' size class distributions and local information. Biodiversity and Conservation 7(10):1261-1275.

Maundu, P.M. 1995. Methodology for collecting and sharing indigenous knowledge: A case study. Indigenous Knowledge and Development Monitor 3(2):3-5.

Martin, G.J. 1995. Ethnobotany. A Methods Manual. Chapman \& Hall, London.

Mesfin, T. 1997. Neglected Treasure: An Overview of Ethiopia's Vegetation. Ethiopian Tree Fund Foundation. www. addis.etff.org/mesfin.pdf (accessed April 2008).

Mourão, J.S., H.F.P. Araujo \& F.S. Almeida. 2006. Ethnotaxonomy of mastofauna as practiced by hunters of the municipality of Paulista, state of Paraíba-Brazil. Journal of Ethnobiology and Ethnomedicine 2:19.

Pagella, T., C. Choocharoen, P. Preechapanya, C. Moss \& F.L. Sinclair. 2002. Local Ecological Knowledge about Watershed Functions in Northern Thailand: A guide to using the Agroecological Knowledge Toolkit (AKT). http:// akt.bangor.ac.uk/documents/ThaiGuide.pdf. University of Wales, UK; World Agroforestry Centre, Royal Forest Department, Thailand.

Pardo-de-Santayana, M., J. Tardío, E. Blanco, A.M. Carvalho, J.J. Lastra, E. San Miguel \& R. Morales. 2007. Traditional knowledge of wild edible plants used in the northwest of the Iberian Peninsula (Spain and Portugal): A comparative study. Journal of Ethnobiology and Ethnomedicine 3:27.

Pauline, M. \& W. Linus. 2004. Status of indigenous fruits in Kenya. Pp. 36-62 in Review and Appraisal on the Status of Indigenous Fruits in Eastern Africa. A synthesis report for IPGRI-SAFORGEN Edited by B. Chikamai, O. Eyog-Matig \& D. Kweka. IPGRI, Nairobi, Kenya.

Pfeiffer, J.M. \& R.J. Butz. 2005. Assessing cultural and ecological variation in ethnobiological research: The importance of gender. Journal of Ethnobiology 25(2):240278.

Puri, R.J. \& C.R. Vogl. 2005. A methods manual for ethnobotanical research and cultural domain analysis with analysis using ANTHROPAC. (Unpublished). 
Quinlan, R. 2005. Considerations for collecting freelists in the field: Examples from ethnobotany. Field Methods $17(3): 1-16$.

Redzic, S.J. 2007. Wild edible plants and their traditional use in the human nutrition in Bosnia-Herzegovina. Ecology of Food and Nutrition 45:189-232.

Setalaphruk, C. \& L.L. Price. 2007. Children's traditional ecological knowledge of wild food resources: A case study in a rural village in Northeast Thailand. Journal of Ethnobiology and Ethnomedicine 3:33.

Shrestha, P.M. \& S.S. Dhillion. 2006. Diversity and traditional knowledge concerning indigenous food species in a locally managed forest in Nepal. Agroforestry Systems 66(1):55-63.

Sinha, R. 2003. Beyond cardsorting: Free-listing Methods to Explore User Categorizations. Technical report. Boxes and Arrows. www.boxesandarrows.com/view/beyond cardsorting_free_listing_methods_to_explore_user_categorizations (accessed January 2008).

Smith, J.J. 1993. Using ANTHROPAC 3.5 and a spreadsheet to compute a free-list salience index. Cultural Anthropology Methods 5(3):1-3.
Statistical Package for the Social Sciences for Windows (SPSS). 06.09.2006. Release 15.0.0. SPSS Inc. 19892006.

Styger, E., J.E.M. Rakotoarimanana, R. Rabevohitra \& E.C.M. Fernandes. 1999. Indigenous fruit trees of Madagascar: Potential components of agroforestry systems to improve human nutrition and restore biological diversity. Agroforestry Systems 46:289-310.

Sutrop, U. 2001. List Task and a Cognitive Salience Index. Field Methods 13(3): 263-276.

Tigist, W., A. Zemede \& E. Kelbessa. 2006. Ethnobotanical study of food plants around 'Dheeraa' town, Arsi, Ethiopia. Ethiopian Journal of Science 29(1):71-80.

Van Den Eynden, V., E. Cueva \& O. Cabrera. 2003. Wild foods from Southern Ecuador. Economic Botany 57(4): 576-603.

Wong. J., R. Lysinge, D. Kenfack, H. Healey \& J. Hall. 2002. Naming and Recognition of Species in Participatory Biodiversity Inventory. www.etfrn.org/ETFRN/WORKSHOP/BIODIVERSITY/documents/wong1.pdf (accessed December 2007). 